\title{
Lima Vaz: entre a negação da metafísica e a anacronia da razão absoluta pela epistemologia da modernidade
}

\section{Lima Vaz: between denial of metaphysics and the anacronym of absolute reason for the epistemology of modernity}

\author{
Savio Gonçalves dos Santos \\ https://orcid.org/0000-0001-9314-8343 - E-mail: oivasavio@gmail.com \\ Gabriele Cornelli \\ https://orcid.org/0000-0002-5588-7898 - E-mail: gabriele.cornelli@gmail.com
}

\begin{abstract}
RESUMO
A perda da capacidade de compreensão do tempo presente, marcada pela instrumentalização da razão, abandonando a dimensão metafísica, atinge a própria condição existencial humana, gerando uma anacronia. Diante disso, faz-se necessário apresentar e compreender as causas que levaram a essa condição, a partir da construção de uma fenomenologia da modernidade, através da leitura de Henrique Cláudio de Lima Vaz. A partir daí, será possível estabelecer um caminho que consiga explicar o contexto da sociedade atual, sua complexidade e a geração de seu enigma: a inexistência de um ethos. Inexistindo o ethos como referência fundante do ethos-hexis, a praxis perde seus referenciais, sendo orientada não pelo finalismo do logos - absoluto da razão -, mas pelas necessidades meramente objetificadas, marcadas pelo relativismo dos valores e por práticas egoístas. De maneira direta, essa alteração na realidade tempo-histórico-social-ética fará com que o humano acabe por perder sua liberdade e, consequentemente, sua identidade.
\end{abstract}

Palavras-chave: Negação da metafísica. Anacronia da razão. Epistemologia da modernidade. Enigma da modernidade. 


\begin{abstract}
The loss of the ability to understand the present time, marked by the reason instrumentalization abandoning the metaphysical dimension, reaches the human existential condition itself, generating an anachrony. Given this, it is necessary to present and understand the causes that led to this condition from the construction of a modernity phenomenology, through the reading of Henrique Cláudio de Lima Vaz. From there, it will be possible to establish a way that can explain the context of today's society, its complexity and the generation of its enigma: the inexistence of an ethos. The absence of ethos as the founding reference of ethos-hexis, praxis loses its references, being guided not by the finalism of logos - the absolute of reason -, but merely objectified needs, marked by the relativism of values and selfish practices. Directly, this change in the time-historical-social-ethical reality will cause the human to end up losing his freedom and, consequently, his identity.
\end{abstract}

Keywords: Negation of metaphysics. Anachronism of reason. Epistemology of modernity. Enigma of modernity.

\title{
Introdução
}

A filosofia, em sua proposição histórica, sempre se voltou para o questionamento transformador, com o objetivo de alcançar e promover a episteme. O movimento fundamental, instaurado por Parmênides no fragmento $6 \mathrm{~b}$, permanece dinamicamente no contexto da modernidade. Para além da proposição ontológica, a disposição reflexiva convida à análise das condições inversas, impeditivas à razão absoluta; por óbvio, o não ser não é, apesar do permanente esforço da ineptidão, por vezes oriunda da doxa.

O dispor bases para fundamentar a investigação acerca da episteme, faz erigir uma fenomenologia da modernidade. Tal feito, justifica-se pelo necessário resgate da significação da existência humana - posta à prova pela modernidade lacerante -, a partir de uma análise histórico-cultural-filosófica, não sem se preocupar com a dimensão espiritual: eis o movimento. Compor uma fenomenologia da modernidade supõe voltar a atenção para a própria história do humano e sua práxis cultural; seu modo de ser e agir, vislumbrando os impactos das ideias "[...] elaboradas no mundo intelectual na organização social, nas instituições, na escala dos valores, nas crenças e, finalmente, na consciência comum" (VAZ, 2012, p. 12). É, portanto, o paradoxo inicial da filosofia, recolocado no contexto da vida, onde se desenvolve um saber racional com a intenção de compreender a realidade (VAZ, 2002, p. 83); sua tarefa primordial, restaurando a sensatez.

O itinerário de uma fenomenologia da modernidade propicia a percepção de que há um novo humano em vias de surgimento, a partir de um modelo completamente diferente daquilo que se tinha como referência. Esse entendimento obriga a filosofia - como aquela que tem por função questionar o tempo presente - a propor a seguinte indagação:

Como se constitui o novo sistema de ideias e de representações do mundo, do próprio ser humano e da transcendência que desencadeou o irresistível processo de transformação histórica do qual emergiu a modernidade? (VAZ, 2012, p. 29).

A resposta direta a essa pergunta obriga o levantamento do contexto temporal em que toda a mudança ocorre, bem como das consequências práticas desse movimento. $O$ ponto de partida se dá no entendimento dos grandes eventos intelectuais da história. O desenvolvi- 
mento da razão grega - entendido como primeiro evento - não representa somente o surgimento da criticidade ou da autofundamentação filosófica. Uma vez transformada a razão em fonte primeira da criação simbólica de um povo - especificamente o grego-, há a substituição das disposições mítico-poéticas pela lógica racional e seu ordenamento. Na prática, há nova fundamentação social em suas bases de sustentação e explicação; uma inédita visão de mundo que coloca a Ideia - em sua busca verdadeira - como a essência do humano, para, a partir dela, explicar o contexto do real.

A segunda consideração importante nesse breve percurso histórico que se delineia, é o momento de passagem da filosofia antiga para a teologia cristã; ou a assimilação de uma pela outra (VAZ, 2012, p. 29). Tal assimilação não se deu somente no campo teórico-conceitual: ela provocou uma releitura da origem do humano, o surgimento de uma nova concepção de Deus e de uma original personificação de divindade, o que desloca o problema do homem-natureza (VAZ, 2002, p. 104), pois:"[...] ao cosmocentrismo da antropologia antiga (identidade da Natureza e do divino), substitui-se o teocentrismo da antropologia cristã (radical diferença de Deus e da Natureza)" (VAZ, 2002, p. 104). Assim,

A natureza perde a sua prerrogativa de arché ou princípio originário e de kanon ou regra última do agir humano, como também o de ser o télos, o fim que acolhe definitivamente e reabsorve no seu seio todos os caminhos do homem. Com efeito, ela deixa de ser o Lógos originário, ordenador e normativo segundo os estoicos, atribuição agora conferida ao Lógos de Deus, por quem todas as coisas foram feitas (VAZ, 2002, p. 104).

O lançar da Ideia como fundamento da natureza humana, portanto o Uno que explicava o múltiplo, para a propositura de um Deus pessoal como o lógos criador do universo, o Absoluto, que exerce o domínio sobre o mundo e a história, obriga o homem a repensar o seu lugar na natureza e na própria história. Há uma espécie de destituição da dimensão sobrenatural, presente até então no humano, que se transfere para uma divindade pessoal, forçando o humano a trilhar um novo caminho, que o leve de volta para a transcendência; "ascensus ad Deum per scalam creaturarum" (VAZ, 2002, p. 105).

O terceiro movimento histórico que marca a mudança promovida na modernidade, advém das transformações ocorridas no campo cultural. Não se trata de remontar uma espécie de roteiro doutrinal da cristandade, mas de complementar algumas posições, à luz das transformações culturais, que, unindo-se àquelas analisadas anteriormente, constroem esse corpo fenomenológico da modernidade. Nesse sentido, a principal referência de alteração cultural foi a retirada do princípio sacral da natureza. É a mudança de sentido do arché primordial que acabou levando à dessacralização realizada pela tecnociência moderna. Como consequência desse evento, o cristianismo também acaba perdendo sua centralidade, dando lugar, no que tange à proposição de valores e ideias, às proposições e descobertas científicas. Assim, a dinâmica natureza-cultura assiste, e adere, à mudança do mundo "[...] pré-científico e pré-técnico para o mundo científico-técnico" (VAZ, 2002, p. 108). Como consequência desse movimento científico, tem-se a "[...] unificação e homogeneização da Natureza sob a égide dos modelos físico-matemáticos que se sucedem de Newton a nossos dias" (VAZ, 2002, p. 108), que modifica a compreensão de mundo, questiona a presença do humano nesse mesmo mundo e estabelece uma nova ideia de cultura que se converte no problema da modernidade.

É a cultura entendida como razão ativa, que avança sobre a natureza oferecida aos seus projetos, para transformá-la, criando assim um mundo humano em face do qual não deverá subsistir, em princípio, uma natureza independente ou indiferente (VAZ, 2002, p. 108). 
O que se percebe, portanto, é que a relação humano-natureza acaba por se converter no estopim da modernidade, levando à pergunta motriz: "quais os fins de uma cultura que tem como matriz a razão científica e que deve submeter aos padrões de racionalidade dessa matriz todas as suas obras em todos os seus campos: ético, político, artístico, religioso?" (VAZ, 2002, p. 109). Admitindo, portanto, ser a cultura o espaço de ação da filosofia, e seu instrumento o questionamento, é por essa mesma filosofia que se buscará estabelecer considerações acerca da questão fundamental do homem lançado na história: a busca pelo sentido do ser e do existir mediante a negação da metafísica e da razão absoluta.

Para tanto, faz-se necessário partir da reflexão analítica dos aspectos que caracterizam essa modernidade; é um voltar-se sobre si mesmo, visando os pontos fundantes que levam à eclosão de uma crise, promovida e alimentada na modernidade. Na prática, o que se propõe é o"[...] estudo da refração das ideias elaboradas no mundo intelectual, na organização social, nas instituições, na escala dos valores, nas crenças e, finalmente, na consciência comum" (VAZ, 2012, p. 112). A escolha da modernidade se deve, primordialmente, por conta da obrigação do filósofo - como aquele que deve pensar o seu tempo na inteligibilidade radical, de apontar as evidências da existência da doxa em detrimento da promoção da aletheia e da episteme - busca pela totalidade do ser. Esse movimento é percebido ao se propor compreender o humano moderno e as transformações palas quais passa a cultura moderna; especialmente pela rejeição à dimensão transcendental/metafísica. $O$ impacto primeiro dessa condição será sentido na passagem da primazia da essência - característica do pensamento antigo - pela existência, motivada pelas transformações ocorridas no então século XIII, fortemente marcada pela retração da metafísica, chegando finalmente ao seu ponto alto: o Cogito cartesiano - especificamente em 1629, ano em que Descartes lança seu Regulae ad directionem ingenii (DESCARTES, 2011, p. 101). Essa ruptura histórica ocasionará, como consequência direta, uma crise dos valores que impactará a cultura. Tal condição passa a dificultar o próprio entendimento do ser e da sua existência - negativa da razão absoluta.

\section{Traços intelectuais da modernidade}

A definição de modernidade pode ser apontada, por primeiro, provinda do "[...] advérbio latino modo que significa primeiramente "há pouco" ou "recentemente" (modo veni, "cheguei há pouco")" (VAZ, 2002, p. 225), estabelecendo uma relação direta com a "novidade" que se apresenta nas questões ora debatidas. entretanto, o uso do termo modernidade se encontra desgastado, tendo se convertido quase que em um objeto utilizado como referencial de moda. Está na moda falar da modernidade.

O aspecto primeiro é observar, que o uso do termo deve ser tratado como uma categoria filosófica. Isso implica uma distinção fundamental da modernidade filosófica, das adoções de outras áreas, ou outras ciências, como Antropologia, Sociologia ou Política, pois a presente análise está fundada num momento anterior a essas concepções, ou mesmo ao surgimento dessas ciências, em particular. Como assevera Lima Vaz, tomar a modernidade como uma categoria filosófica, significa assumir a prática de uma "[...] leitura do tempo pela razão filosófica" (VAZ, 2002, p. 225). Dessa forma, é possível assumir uma determinada “[...] equivalência conceptual, de modo que podemos afirmar que toda modernidade é fundamentalmente filosófica, ou que toda Filosofia é expressão de uma modernidade que se reconhece como tal no discurso filosófico" (VAZ, 2002, p. 225). Na prática, a proposta se converte na eminente necessidade de se traduzir essa modernidade por meio da filosofia. 
O segundo ponto a se considerar, na busca pela explanação do termo modernidade, reside na compreensão de que ela pode ser considerada "o universo simbólico formado por razões elaboradas e codificadas na produção intelectual do Ocidente nesses últimos quatro séculos e que se apresentam como racionalmente legitimadas" (VAZ, 2012, p. 7). Essa posição significa considerar todos os referenciais recebidos pelo humano, seja no campo filosófico ou científico e que, de alguma forma, afetam a realidade, a cultura e a história desse mesmo humano. Trata-se, de maneira direta, do "terreno da urdidura das ideias que vão, de alguma maneira, anunciando, manifestando ou justificando a emergência de novos padrões e paradigmas da vida vivida" (VAZ, 2012, p. 12); e, ainda, "o domínio da vida pensada, o domínio das ideias propostas, discutidas, confrontadas nessa esfera do universo simbólico que [...] denominamos mundo intelectual" (VAZ, 2012, p. 12).

Com o intuito de estabelecer um caminho para a análise dos principais aspectos da concepção de modernidade, o presente trabalho levantará três posições distintas, que se unem para promover a dialética do tempo presente, "[...] continuidade e descontinuidade, primeiramente, entre mito e razão, depois entre Filosofia antiga e Teologia cristã, finalmente entre teologia cristã e razão moderna" (VAZ, 2012, p. 11). Partindo do estabelecimento dos traços intelectuais da modernidade, é possível alcançar o fator principal gerador da crise, a (in)consciência do tempo, o que revela o enigma da modernidade e, como consequência, abre espaço para o desenvolvimento de uma crise profunda, que alcança seu ápice na proposição do niilismo metafísico e ético. Essa condição altera a disposição do sentido do ser, modifica a relação com o absoluto, com a natureza, e coloca a objetificação como caminho para a superação da crise. Essa pseudoideia de liberdade arrasta o ser para seu ponto mais obscuro, em que o seu futuro passa a ser incerto, graças à negação da essência metafísica pela existência da razão moderna.

Os traços intelectuais da modernidade, seus fundamentos epistemológicos e, obviamente, práticos - pois alteram a disposição histórico-cultural -, são derivações diretas das "raízes" teóricas oriundas da Idade Média. Essas raízes são eminentemente intelectuais, pois é no campo da proposição das ideias que se iniciam a transformação e a disposição de um sistema simbólico novo, que, posteriormente, dará vida à razão moderna. Uma vez apresentados os eventos históricos específicos, faz-se necessário estabelecer, três traços fundamentais para a compreensão do tempo presente (VAZ, 2012, p. 14-15).

O primeiro traço diz respeito à "[...] relação de objetividade do ser humano com o mundo" (VAZ, 2012, p. 15). Essa ideia parte da aceleração da passagem do mundo natural ao mundo técnico, após o século XVII ${ }^{1}$. Esse movimento faz com que haja, por parte do humano, uma adaptação, quase forçada, ao mundo da "exatidão", abandonando o mundo do "aproximadamente". Aqui, a capacidade de inovação tecnológica, que se perfaz de uma velocidade de transformação inigualável, torna-se um dos referenciais primordiais "[...] de um tempo rigorosamente regido pelo presente da razão técnica" (VAZ, 2012). Tal condição modifica a relação do indivíduo com o seu mundo objetivo, na qual o ser cede seu lugar cognoscente - que tem na busca da razão o movimento primeiro - aos objetos em si, que acabarão como os responsáveis pela significação do ser na modernidade (VAZ, 2012).

O segundo traço intelectual "[...] manifesta-se no domínio das relações intersubjetivas" (VAZ, 2012). Essa condição se faz presente no contexto da modernidade, com o aparecimento

\footnotetext{
${ }^{1}$ Cumpre ressaltar que quando Lima Vaz se refere à formação do mundo moderno, bem como apresenta sua disposição como técnico, ele não propõe uma compreensão idealista que se sobreponha ao desenvolvimento da cultura material. Para ele, existe uma intercausalidade dialética entre os componentes infraestruturais e estruturais da cultura, que se modificam segundo sua própria dinâmica, mantendo uma relação com as disposições ideais do simbolismo da razão. Ver Vaz (2012, p. 15).
} 
da categoria indivíduo. Aqui, indivíduo passa a ser definido como o ser social, que passa a compreender e a depender a/da relação do tempo, e a interferência direta deste no contexto da vida. A capacidade de mensuração do tempo, assumida no contexto da modernidade, acarretará mudanças na prática formativa, laboral, lúdica, familiar. Tal fenômeno está "[...] inadequadamente descrito como individualismo" (VAZ, 2012); pois, em verdade, é, na modernidade, que o humano perde a sua individualidade, sua identidade, dando lugar à dinâmica do ser outro, ou ser no outro. A dimensão social, em verdade, acaba por promover a alienação do ser, pois o força a alcançar uma suposta autonomia, a se posicionar no contexto das inúmeras propostas sociais, quando, na verdade, o que se assiste é a uma dissolução da capacidade de autofundamentação e do questionar-se. Há o abandono do eu em detrimento do outro; ponto paradoxal da modernidade, pois ao mesmo tempo em que há o encontro da subjetividade, pelo sum cartesiano, abre-se espaço para a negação dessa mesma subjetividade ao abandonar sua identidade (VAZ, 2012, p. 16).

O terceiro traço, marcado como o mais complexo e significativo, manifesta-se na "[...] relação fulcral do ser humano enquanto habitante de um universo de símbolos que denominamos relação de transcendência" (VAZ, 2012, p. 16). Nesse contexto reside a possibilidade única de que a vida humana seja possível, pois apresenta uma estrutura necessária para o universo simbólico. $O$ evento modernidade recoloca essa estrutura, propondo a abolição da dimensão metafísica e a colocação da existência humana como fonte primordial de "[...] autotranscendência desdobrando-se na esfera da imanência: instituições do universo político, na construção do mundo técnico, na concepção autonômica do agir ético, na fundamentação teórica, da visão de mundo" (VAZ, 2012, p. 16).

A profunda mudança provocada por essa colocação da existência do humano como autotranscendente - que desloca a proposta do Princípio transcendente - fez-se possível graças ao surgimento de uma Razão estruturalmente operacional, que se diferencia em inúmeras outras racionalidades. "Ela impõe historicamente a centralidade do Eu racional e fundamenta a sequência: Eu transcendental, Indivíduo universal, Eu social" (VAZ, 2012, p. 17). Essa sequência passa a responder pela instituição e avaliação dos sentidos vividos pelo humano, o que passa a demarcar uma reviravolta na disposição anterior, na qual essa função era exercida pela existência do então Princípio transcendente (VAZ, 2012, p. 16). Entretanto, apesar de ser o ponto sensível do itinerário intelectual da modernidade, faz-se necessário uma ressalva quanto à condição transcendental: "[se] partirmos em busca da raiz intelectual mestra, da qual brotou o paradigma da autotranscendência, iremos encontrá-la muito provavelmente no tema matricial do pensamento na Idade Média: as relações entre fé e razão" (VAZ, 2012, p. 17).

Apesar de não figurar como um traço intelectual da modernidade, a busca pela definição de uma dimensão axiológica acaba sendo um dos pontos mais discutidos dentro do universo de estudos e pesquisas. Entretanto, o esforço precisa ser concentrado numa disposição genética dessa mesma modernidade. Esse caminho, porém, não abandona a leitura hermenêutica clássica que fomenta o caminho da análise do tempo presente: a dialética entre continuidade e descontinuidade, mencionada anteriormente. A aplicabilidade dessa dialética busca encontrar o momento de ruptura entre o eminentemente novo da modernidade e o esquecimento do antigo. É somente a partir da ruptura que se torna possível a interpretação da existência histórica do humano (VAZ, 2012, p. 18). Cumpre observar que o

[...] paradigma da ruptura só é pensável na pressuposição de uma continuidade que se rompe. Essa pressuposição nos impõe pensar o novo como negação dialética do antigo que lhe dá origem. No acontecer histórico não há, evidentemente, nenhuma emergência do absolutamente novo. A continuidade do tempo subjaz a todas as mudanças. O paradigma 
da ruptura deve ser inicialmente formulado segundo os termos da relação que continua a unir antigo e o novo no desenrolar histórico de sua separação (VAZ, 2012, p. 18).

Admitindo que a modernidade advém de uma ruptura com a Idade Média, fundamentalmente cristã, um dos pontos essenciais acabará se vertendo para a negação do próprio cristianismo, bem como de suas bases axiológicas. As proposições que surgirão da modernidade serão, em sua maioria, argumentos, ideias, ações, princípios, diretamente opostos às definições cristãs, culminando com o lluminismo no século XVIII. Entretanto, não é possível, como visto, desvincular a modernidade do cristianismo, pois é exatamente aí que estão “[...] propostos diversos paradigmas e, neles, as categorias de uma axiologia da modernidade. No centro dessas interpretações, está o fenômeno da ruptura" (VAZ, 2012, p. 18). O movimento de ruptura não atinge somente o campo histórico, mas avança em outros pontos de estabilidade da vida como um todo, alterando a estrutura social e cultural: “[...] crenças, ideias, mentalidades, atitudes, práticas sociais" (VAZ, 2012, p. 18).

Toda essa análise primeira, em busca dos traços intelectuais da modernidade, aponta as profundas transformações ocorridas a partir do advento da razão moderna, que lançou suas teias, inclusive, na filosofia. Essa proposição de contextos e novas premissas provoca uma mudança na relação do humano com o tempo, o que altera a própria consciência do tempo - símbolo fundamental para organização do mundo. "Verifica-se aqui a emergência de um presente qualitativamente novo onde se exerce o ato da razão" (VAZ, 2012, p. 13). A alteração da consciência do tempo abre margem para o surgimento do enigma da modernidade, que culmina com o eclodir da crise.

\section{Negação e anacronia: ciência, metafísica e razão}

A crise da modernidade não é propriamente sobre o tempo moderno em si; trata-se da disposição do surgimento de novas ideias e proposições que se apresentam como referenciais para a definição e a explicação do ser e do sentido; de sua existência a partir da capacidade de indagar-se e, nessa indagação, analisar os efeitos do tempo presente. Assumindo que uma das consequências dessa mesma modernidade seja a objetificação do humano, em que o desejo em ter supera o ser, ou onde o ser acaba sendo definido pelo ter, invertendo a relação do conhecimento, a modernidade se esforça em apresentar inúmeras propostas para esse humano, o que leva à promoção de crises, direcionando a condição humana para o nada; para o niilismo.

[...] a modernidade significa a reestruturação modal na representação do tempo, em que este passa a ser representado como uma sucessão de modos ou de atualidades, constituindo segmentos temporais privilegiados pela forma de Razão que neles se exerce (VAZ, 2002, p. 236).

É no tempo histórico, propriamente, que a modernidade se constroi, a partir da proposição de uma nova forma da razão, que contrapõe as definições anteriores. É a partir dessa razão imanente que se dará a organização do sistema simbólico moderno. Essa nova relação do homem com o tempo inaugurará uma nova dinâmica na captação e interpretação desse mesmo tempo, tendo como efeito direto dessa mudança estrutural o desenvolvimento do "[...] ciclo de uma nova modernidade que irá reivindicar explicitamente, em cada uma das suas fases, essa propriedade eminentemente axiológica do ser moderno"(VAZ, 2002, p. 236). Dessa forma, tanto a filosofia quanto as ciências modernas 
[...] caracterizam-se pelo abandono da concepção antiga do tempo cosmológico recorrente e eterno, "imagem móvel da eternidade imóvel". Ela foi substituída por duas novas representações do tempo: o tempo físico dos fenômenos, introduzido como variável das equações do movimento e relativo aos procedimentos de medida do observador, e o tempo histórico dos eventos humanos (VAZ, 2002, p. 263).

A relação da filosofia com o tempo, surgida nessa modernidade, especialmente demarcada pelo pensamento de Descartes, trará uma nova proposta de interpretação dessa mesma modernidade. Nela, encontra-se a disposição fundamental que "[...] tem como princípio a imanentização no próprio sujeito do fundamento que confere ao ato de filosofar seu privilégio no tempo" (VAZ, 2002, p. 263). Se, antes, no passado, o tempo religioso, marcado por uma leitura cristã, apresentava-se como original e o único caminho, no qual o evento crístico, da Encarnação e Ressurreição figurava como o meio pelo qual se alcançava o sentido e o ser - essência -, agora se apresenta o “[...] 'Eu penso' (cogito) como princípio do discurso filosófico [que] avoca pra si o privilégio de um começo absoluto ou da suprassunção do tempo - anulação do tempo pelo conceito, diz Hegel - no agora privilegiado do saber filosófico" (VAZ, 2002, p. 237). A definição do cogito cartesiano como meio para a explicação do existir do humano promove, assim, a passagem da primazia da essência para a primazia da existência.

O surgimento da razão cartesiana provocará transformações no contexto social, mas, consequentemente, é no humano que se apresentarão os maiores desafios. Essa razão possibilita, agora, a submissão do destino do humano às ações e intenções subjetivas, agindo na natureza, dominando-a e transformando-a. Essa nova condição em que o humano se encontra trará um questionamento que se coloca como um ponto nevrálgico da própria modernidade: “[...] que forma de inteligibilidade se deve pressupor ou pré-compreender no existir como tal, no simples ato de ser?" (VAZ, 2012, p. 98). A resposta encontrada pela modernidade é o desenvolvimento de uma razão científica e de uso operacional, que tem sua eficácia regida pela produção de objetos (VAZ, 2012, p. 101). Dessa forma,

[...] a razão científico-operacional é uma razão intrinsecamente ligada ao agir e ao fazer humanos. Ela observa, estabelece normas, formula hipóteses, enuncia teorias, verifica leis, propõe modelos, simula situações, mede e calcula, rege a produção de objetos (VAZ, 2012, p. 101).

Essa dialética do produzir-usar não modifica somente a realidade do agir-fazer do humano: ela lança suas considerações sobre a existência do humano, pressupondo "[...] o estar-no-mundo do sujeito racional, o seu simples existir enquanto dado a si mesmo, em meio às coisas que igualmente lhe são dadas" (VAZ, 2012, p. 101). Essa situação na qual se encontra o humano moderno, que Lima Vaz denomina situação ôntico-primária (VAZ, 2012, p. 101), não consegue ser resolvida, explicada, pela razão científico-operacional. Assim, permanece o problema da inteligibilidade do esse, derivado das crises do século XIII, oriundas da antiguidade grega, como um dos principais entraves da razão moderna. Entretanto, cabe ressaltar que a "[...] existência, no seu simples ato de existir, é irredutível aos procedimentos operacionais da razão" (VAZ, 2012, p. 102), pois essa mesma razão pode "[...] representar, explicar transformar, modificar, organizar, projetar. Mas não pode criar" (VAZ, 2012, p. 102-103). Essa impossibilidade de que a Razão moderna explique a condição existencial do humano provocará, de maneira direta, irracionalismos que se verificarão nas “[...] crenças, na filosofia, nas ideologias, na política, nas condutas, que nenhuma estratégia teórica ou prática consegue controlar" (VAZ, 2012, p. 103).

O descontrole racional promovido pela razão científica ocasionará três situações complexas, que vão de encontro com a possibilidade da explicação do ser e do sentido. A primeira 
será a modificação do lugar do homem no mundo, deixando de ser para assumir o papel de sujeito, e assim, ocupar o centro do universo inteligível; ato que Lima Vaz chamará de descentração ${ }^{2}$. O efeito direto da descentração será a modificação profunda nos referenciais axiológicos, ocasionando a transformação do universo simbólico da modernidade.

A segunda situação reside no problema do fundamento do ato de filosofar. Pelo efeito da descentração, o ato de filosofar se desloca do transcendente, para "[...] residir no próprio sujeito do ato de filosofar, em cuja imanência se dará a suprassunção do tempo empírico na atualidade de um saber que, finalmente, irá proclamar-se absoluto" (VAZ, 2002, p. 112). Tal modificação impactará diretamente na relação de transcendência, pois não haverá, a partir de agora, a dimensão metafísica como aquela que era a responsável por tratar das "coisas humanas", modificando a cultura. A filosofia, com seu exercício de colocar em questão e dar razão, apresentada como Metafísica da cultura - que propõe a criação de um modelo ideal para a sobrevida do humano -, acaba lançada, como consequência, num "programa de mundanização", como anteriormente apontado. O pano de fundo, porém - dessa questão que envolve a filosofia - é a cultura em sua significação, que se converte em referência para a dimensão econômica, social, política e ética. A impossibilidade de encontrar respostas para o problema da cultura, provocada pelos efeitos da razão moderna, lança ao humano o seu maior desafio: "[...] a antiga interrogação sobre os fins da cultura" (VAZ, 2002, p. 112) - nisto reside a terceira situação; e se deve, principalmente, pelo fato de que ela

[...] apresenta-se estruturalmente constituída de duas faces: a face objetiva, enquanto ela é pragma ou obra do homem, e a face subjetiva enquanto é práxis ou ação humana. $\mathrm{Na}$ face subjetiva, a cultura é essencialmente axiogênica, ou geratriz de valor como qualidade inerente à ação humana; na sua face objetiva ela é essencialmente axiológica, pois a obra humana é sempre portadora e significativa de algum valor. Vale dizer, em outras palavras, que a cultura é coextensiva ao ethos: ao produzir o mundo da cultura como mundo propriamente humano onde se exerce a sua prática e onde se situam as suas obras [...] (VAZ, 2002, p. 127).

A partir do momento em que a cultura se converte em ethos, ela se torna a morada que promove a significação e apresenta os valores necessários para o entendimento do real. Assim, será o ethos o direto responsável pela sobrevivência humana, por onde se dará a compreensão do mundo e de si mesmo, apontando as possíveis direções do dever-ser no contexto histórico (VAZ, 2002, p. 113). Isso significa assumir que, "toda cultura, pois, na sua dimensão simbólica, é essencialmente ética e é no seu ethos que ela situa o ponto de convergência de todas as suas manifestações [...]" (VAZ, 2002, p. 128). É nessa relação estabelecida entre a história e cultura e a cultura e o ethos que se alcança o cerne da crise da modernidade; "[...] uma civilização sem ethos e, assim, impotente para formular a ética correspondente às suas práticas culturais, políticas e aos fins universais por ela proclamados" (VAZ, 2002, p. 126). O abandono da cultura, bem como a impossibilidade da criação de um ethos universal, leva à negação do ser - "[...] a perda do humano no agir e na obra do homem" (VAZ, 2002, p. 96) -, tem-se, assim, um niilismo (VAZ, 2002, p. 26); em suas duas acepções: niilismo metafísico e niilismo ético.

\footnotetext{
${ }^{2}$ A descentração pode ser definida como a inversão da centração tópica que determinava a ligação do homem à terra, o que promovia a descentração metafísica que o levava ao encontro do Absoluto transcendente. Sobre essa questão, ver Vaz (2002, p. 239-249).
} 


\section{Conclusão}

Reconhecendo o avanço promovido no campo técnico-científico, portanto, dos objetos, a razão moderna, de fato, avançou. Entretanto, apesar de ter produzido inúmeros artefatos que expandiram a vida e ampliaram o domínio da natureza, essa razão não consegue determinar seus traços axiológicos. O impacto direto desse evento se dará na habilidade e na possibilidade de explicação da existência humana. O humano, assim, não consegue pensar seu existir em meio ao contexto de produções objetivas. O que se tem, em verdade, é a "[...] racionalização de todas as manifestações da vida humana e de todos os fenômenos do universo" (VAZ, 2012, p. 103), que leva ao niilismo metafísico e a anacronia da razão absoluta.

A alteração nas relações do humano com os objetos do mundo - categoria de objetividade (VAZ, 2012, p. 253) - arrastou as formas de conhecimento e de produção para os modelos operativos, teóricos e técnicos, dando margem para o desenvolvimento de objetos destinados, pura e simplesmente para atender às novas necessidades vulgares que passam a dar sentido à vida. Convém observar que a possibilidade do encontro com o ser tem início na objetividade mundana - na qual também se concretiza a finitude do humano - e se apresenta na limitação espaço-temporal, fundamento da dimensão ontológica, que caracteriza esse humano como "[...] ser entre seres" (VAZ, 2012, p. 253). Portanto, "uma transformação profunda da objetividade mundana traz consigo uma mutação não menos profunda do estatuto natural ou ôntico do nosso ser-no-mundo e, portanto, da sua inteligibilidade ontológica" (VAZ, 2012, p. 254).

Isso significa admitir, portanto, que "[...] a pressuposição da imanência absoluta da razão finita deve conviver com o sem-razão do simples existir" (VAZ, 2012, p. 103) - a condição que aprofunda a presença do niilismo no contexto moderno. Assim, "o exílio da metafísica para fora dos domínios do conhecimento reconhecido como legítimo e sensato foi decretado ao ser estabelecida a soberania do sujeito sobre todas as províncias do saber [...]"(VAZ, 2002, p. 183-184). $\mathrm{O}$ “[...] niilismo metafísico não é um destino inscrito na nossa tradição de pensamento, mas a recusa do princípio e fundamento transcendente da razão humana [...]" (PERINE, 2003, p. 64). Portanto, o erigir de uma razão meramente matemático-experimental exclui, de suas bases, as realidades transcendentes, que fazem com que a metafísica, exilada do domínio da razão, emigre para "o mundo do mito" (PERINE, 2003, p. 366). O impacto desse exílio poderá ser assistido nos excessos da civilização ocidental, marcada pela busca incessante do prazer e da satisfação das vontades subjetivas; o que acaba dando margem para o surgimento de uma espécie de ética da subjetividade, anulando a possibilidade de existência do juízo de valor, fundando um niilismo ético.

\section{Referências}

BARBIERI, P. Sobre a Natureza, de Parmênides de Eleia. Revista Brasileira de Estudos Clássicos, v. 33, n. 1, p. 311-325, 2020.

DESCARTES, R. Regulae ad directionem ingenii. Cogitationes privatae. Hamburg: Felix Meiner Verlag, 2011.

PARMÊNIDES. Da Natureza. 2a ed. Petrópolis: Loyola, 2002.

PERINE, M. Niilismo ético e filosofia. In: Diálogos com a cultura contemporânea. São Paulo: Loyola, 2003. 
VAZ, H. C. de L. Escritos de Filosofia III: Filosofia e Cultura. 2a ed. São Paulo: Loyola, 2002.

VAZ, H. C. de L. Morte e vida da filosofia. Pensar, v. 2, n. 1, p. 08-23, 2011.

VAZ, H. C. de L. Escritos de Filosofia VII: raízes da modernidade. 2a ed. São Paulo: Loyola, 2012.

\section{Sobre os autores}

Savio Gonçalves dos Santos

Doutor. Universidade de Brasília. Programa de Pós-graduação em Metafísica.

Gabriele Cornelli

Doutor. Universidade de Brasília. Programa de Pós-graduação em Metafísica.

Recebido em: 24/04/2021.

Aprovado em: 29/05/2021.
Received: 24/04/2021.

Approved: 29/05/2021. 